\title{
Preoperative anaemia in surgical patients: Intravenous iron and erythropoiesis-stimulating agents (ESAs) to the rescue
}

\author{
Arinze D.G. Nwosu \\ Department of Anaesthesia, National Orthopaedic Hospital, Enugu, Nigeria
}

\begin{abstract}
Despite the propensity for allogeneic blood transfusion by clinicians, the space for this therapy is steadily being contracted by limited evidence of benefit from its use in most situations, adverse effects of its use, high cost, limited supply and rejection by some religious faithfuls. Available literature concedes to the high prevalence of preoperative anaemia in diverse surgical settings irrespective of geography and reflects the global burden of anaemia. Beyond the poorer surgical outcome directly attributed to preoperative anaemia, it has also been recognized as the major predictor of allogeneic blood transfusion with attendant morbidity and mortality. The concept of Patient Blood Management (PBM) seeks to minimize exposure of patients to allogeneic blood and is based on three pillars of maximizing total red cell mass, minimizing iatrogenic blood loss and harnessing patient's physiological tolerance of anemia. Consequently, PBM places great premium on correcting preoperative anaemia in surgical patients. With the limited success of leucodepletion and other measures at addressing the complications of allogeneic blood transfusions new interest is expanding in PBM. Several of these have been evaluated and among them the use of newer formulations of intravenous iron with or without erythropoiesis-stimulating agents has been most studied and credited with substantial success and good safety profile. Insight is also offered on the oversubscribed misconception of iron overload in $\mathrm{HbSS}$ patients while elucidating on the basis for iron supplementation in proven cases of iron deficiency. Some prevailing barriers, however, threaten the full realization of the potentials of these therapies.
\end{abstract}

Correspondence: Arinze D.G. Nwosu, Department of Anaesthesia, National Orthopaedic Hospital, Enugu, Nigeria.

E-mail: adnwosu@yahoo.com.

Key words: Patient safety; autologous; allogeneic; leucodepletion; surgery; patient blood management.

Conflict of interest: The author declares no conflict of interest.

Funding: None.

Received for publication: 31 June 2020.

Revision received: 26 July 2020.

Accepted for publication: 29 July 2020.

This work is licensed under a Creative Commons Attribution NonCommercial 4.0 License (CC BY-NC 4.0).

${ }^{\circ}$ Copyright: the Author(s),2020

Licensee PAGEPress, Italy

Annals of Clinical and Biomedical Research 2020; 1:91

doi:10.4081/acbr.2020.91

\section{Background}

It is a decade since May 2010 when the World Health Assembly through resolution - WHA 63.12, requested the member states to promote rational use of blood products and the availability of transfusion alternatives including Patient Blood Management (PBM). ${ }^{1}$ Patient blood management refers to multidisciplinary, individualized, best practice strategies implemented for the care of patients who might need a blood transfusion in the course of their treatment. The concept of $\mathrm{PBM}^{2}$ embodies best clinical practice, beyond providing alternative to allogeneic blood transfusion. Emerging global health issues such as the aging population and ever expanding stringent screening requirements with the imposition of restrictions on potential blood donors impact on blood product demand, supply and cost, with predictable shortcomings in blood safety in resource-poor countries. These call for innovative strategies in blood management. Preoperative anaemia is highly prevalent in surgical patients, yet even mild degrees of anaemia have been independently associated with adverse outcome in diverse surgical conditions. ${ }^{3-5}$ In considering patient safety therefore it is deemed imperative to correct preoperative anaemia in elective surgeries in order to avoid the unnecessary exposure of surgical patients to potential adverse effects thereof. Going forward, clinicians should endeavor to understand that preoperative anaemia is not simply an abnormal laboratory value, but an important modifiable risk factor for perioperative morbidity and mortality. In recognition of this crucial clinical consideration, several international practice guidelines ${ }^{6-8}$ have come to recommend that healthcare pathways should be structured to ensure anaemia screening and correction before surgery.

In revealing the principal role of preoperative anaemia in blood transfusion requirement the Austrian benchmark study on blood use in elective surgery had found that despite intercenter variability in surgical blood loss and red cell transfusions in standard surgical procedures, preoperative haemoglobin $(\mathrm{Hb})$ was a main predictor of allogeneic red cell transfusions and that the incidence of preoperative anemia was three times higher in patients that received transfusions compared to those who did not. ${ }^{9}$ Both anaemia and the allogeneic blood transfusion it brings about are harmful to patients, ${ }^{10}$ therefore strategies to correct anaemia before elective surgery are being implemented to conserve scarce blood resource, improve outcome with reduced morbidity and mortality, and save healthcare cost. Rather unfortunately in negating this valid concern for healthcare quality and safety, recent evidence reveals that substantial number of anaemic patients still present in the operating room for major elective surgeries. ${ }^{11-12}$ Thus the aim of this study was to highlight the gap between available evidence-based options and current practice of patient blood management with particular interest in the use of intravenous iron and erythropoiesis-stimulating agents (ESAs) to correct preoperative anaemia. 
A recent systematic analysis has revealed a high global burden of anaemia estimated at $32.9 \%$ with iron deficiency being the most frequent cause of anaemia worldwide while sub-Saharan Africa, Carribean and Southeast Asia had the highest burden. ${ }^{13}$ Iron deficiency is a predominant nutritional anaemia resulting mainly from inadequate dietary intake and increased nutrient losses (parasitic infestations such as malaria, hookworm and schistosomiasis; haemorrhage associated with childbirth and menstruation). It is commonly treated with iron supplementation; oral or parenteral, while the cause of the nutrient loss is evaluated and addressed. Consequently iron intervention by supplementation and food fortification has been pivotal in most global anaemia control programmes. ${ }^{14-15}$ Chronic haemolysis due to genetic $\mathrm{Hb}$ disorders such as sickle cell disease and thalassaemia also contribute significantly to anaemia especially in Africa and Southeast Asia respectively. ${ }^{16}$ Occult anaemia has high prevalence in elective surgical patients and several reports have revealed remarkably high figures. In a meta-analysis by Fowler et al. including 949445 patients scheduled for diverse surgeries some 371594 (39.1\%) were found to be anaemic. ${ }^{5}$ A US-based retrospective study by Musallam et al. reviewed 227,425 patients, of whom 69,229 (30.44\%) had preoperative anaemia. ${ }^{17}$ In another US-based multicentre study Gupta et al. reported a $47 \%$ prevalence of anaemia among 31,857 elderly patients undergoing elective vascular surgery. ${ }^{18} \mathrm{~A}$ recent prospective study in Ghana, which excluded planned day-case surgery and obstetric procedures, reported preoperative anaemia in $54.3 \%$ of the 893 patients studied. ${ }^{19}$ These prevalence rates mirror the burden of anaemia in different populations as reported in the global anemia burden study. ${ }^{6}$

\section{Direct consequences of preoperative anaemia}

There is mounting evidence that preoperative anaemia is associated with increased postoperative morbidity and mortality and this remains valid even after considering the influence of confounding variables and mediator variables. ${ }^{20}$ White et al. studied surgical complications among anaemic and non-anaemic patients undergoing elective surgeries in diverse specialties in Democratic Republic of the Congo and Madagascar $(n=2064){ }^{21}$ They found that severe preoperative anaemia was a predictor of surgical complications amounting to a 33-fold risk of unexpected ICU admission, 7-fold risk of surgical site infection and 2-fold risk of unplanned return to operating room among patients with severe preoperative anaemia compared to those without anaemia. In 2014 the International Surgical Outcomes Study Group conducted a multinational cohort study involving 38,770 elective surgery patients from 27 countries to determine the impact of preoperative anaemia on postoperative morbidity and mortality. ${ }^{22}$ The outcome revealed that while patients with moderate anaemia have a 2.7 fold risk of death those with severe anaemia have a 4-fold risk of death, compared to those who are not anaemic. There was no significant association between mild preoperative anaemia and death after multivariate modelling (OR: 1.05, 0.68-1.63). Morbidity rates similarly increased with the severity of anaemia; as greater rate of infections, cardiovascular complications, ICU admissions, ICU length of stay and hospital length of stay were concomitant with higher degrees of anaemia. However, in contrast to mortality risk which was not significantly affected by mild preoperative anaemia,

even mild anaemia was associated with higher risk of complications. Greenky et al. have also demonstrated that in patients undergoing total joint arthroplasty preoperative anaemia was associated with prolongation of hospital stay and subsequent development of periprosthetic joint infection. ${ }^{23}$ Using a multivariate logistic regression analysis model Grosso et al. presented that among patients undergoing total hip arthroplasty mild preoperative anaemia was a risk factor for mortality (OR: 2.06), renal complications (OR: 2.59) respiratory complications (OR: 1.89), sepsis (OR: 2.01), wound infection (OR: 1.36) and urinary tract infection (OR: 1.44). ${ }^{24}$ In their cohort severe anemia represented higher risk for total complications than mild anaemia (OR: 1.99 versus 1.46). Similarly Abdullah et al. studied the impact of preoperative anaemia on the surgical outcome of 2394 total knee arthroplasty patients and found this comorbidity to be independently associated with prolonged hospital length of stay and increased perioperative blood transfusion. ${ }^{25}$ Evidence from the European Surgical Outcomes Study (EuSOS) group also indicated worse surgical outcomes for patients with preoperative anaemia as adjudged by higher in-hospital mortality, longer hospital length of stay and postoperative admission to intensive care. ${ }^{26}$ Bydon and colleagues investigated the effect of preoperative anemia on 30-day mortality and morbidity rates of 8015 patients who underwent elective neurosurgical procedures using data from a national database. ${ }^{27}$ Their study revealed that those with preoperative anaemia had significantly higher mortality and morbidity compared to those without preoperative anaemia. The higher morbidity rates were observed in respect of pneumonia, unplanned intubation, prolonged ventilation, acute renal failure, urinary tract infection, myocardial infarction, graft failure and sepsis, but not surgical site infection and wound dehiscence. Two US-based studies analysed the impact of severity of preoperative anaemia on surgical outcomes and concluded that even mild degrees of preoperative anemia was associated with progressively worse morbidity and mortality. ${ }^{28,29}$ Quite recently Padmanabhan et al. compared anaemic patients with a matched group of nonanemic patients who underwent cardiac surgery. ${ }^{30}$ They neither found significant association between preoperative anemia and red cell transfusion, nor between red cell transfusion and long-term mortality, but reported that preoperative anemia was independently associated with long-term mortality (OR, 1.70; 95\% CI, 1.46-2.1; $\mathrm{P}<0.001)$.

\section{Indirect consequences of preoperative anaemia}

The indirect consequences of preoperative anaemia relate mainly to its eventual association with greater use of blood products. Beyond the erstwhile known complications of blood transfusion such as transfusion reactions and transmission of infections recent clinical outcomes research have examined the impact of blood transfusion on critically ill patients, surgical patients and cancer patients, among others and have provided additional evidence of their adverse outcomes. In a systematic review and metaanalysis involving 949445 patients, Fowler et al. evaluated the influence of preoperative anaemia on postoperative outcomes. ${ }^{5}$ They found that beside the direct effect of higher morbidity and mortality, preoperative anaemia was associated with five-fold risk of blood transfusion. Cushner and Friedman had also studied 112 consecutive primary total knee arthroplasties and observed that of the patients requiring a transfusion there was no significantly greater drop in haematocrit when compared to patients not receiving a transfusion, and that the need for transfusion was related to preoperative haematocrit and not the intraoperative or postopera- 
tive blood loss. ${ }^{31}$ Several other studies have implicated preoperative anaemia as an independent risk factor for perioperative blood transfusion in major surgeries. ${ }^{32-35}$ This collateral consequence mediated through increased allogeneic transfusion risk has in great measure heightened the concern over preoperative anaemia in surgical patients.

Transfusion-induced immunomodulation with impaired host cellular immune response has been associated with postoperative infections in surgical patients while promotion of tumour growth, recurrence, and metastasis with decreased survival has been reported in surgical oncology patients. ${ }^{36-37}$ In another analysis of the impact of preoperative anaemia and blood transfusion on women undergoing gynecological surgery, preoperative anaemia was independently associated with increased odds of mortality and morbidity, with blood transfusion contributing enormously to these effects ( $61 \%$ of the effect on mortality and $16 \%$ of the morbidity). ${ }^{38}$ Several researchers have reported that morbidity and mortality risk of allogeneic blood transfusion is dose-dependent on the number of red blood cell units transfused. The observational cohort study by Koch et al. to quantify incremental risk associated with transfusion of packed red blood cells in 11,963 patients who underwent coronary artery bypass graft surgery concluded that each unit of red cells transfused is associated with incrementally increased risk for adverse outcome. ${ }^{39}$ Similar dose-dependent increases in morbidity and mortality rates in association with volume of transfused allogeneic blood were reported by other researchers. ${ }^{40}$ Meanwhile perioperative blood transfusion has been implicated as a predictor of hospital length of stay in several studies..$^{25,41}$ The impact of allogeneic blood transfusion on venous thromboembolism risk in patients has also been evaluated and the association between allogeneic transfusions and venous thromboembolism was supported by Grade-I evidence. ${ }^{42}$ Red cell transfusion remains the quickest way to raise $\mathrm{Hb}$ concentration and correct anemia but the foregoing bear testimony to the harm attributable to both the ailment that anaemia represents in this scenario and its treatment with blood. Many of the complications observed in clinical studies have been tagged on both anaemia and blood transfusion. Whether a primary mechanism triggered by the anaemia mediates some harm attributed to blood transfusion has not been elucidated, after all the transfused patients are also anaemic. Thus the mortality and morbidity attributed to blood transfusion may be in part due to the anaemia that indicated the blood therapy in the first instance. I'm not aware of any study yet that evaluated the effect of blood transfusion in non-anaemic patients. In segregating these two factors researchers have embarked on investigating the comparative contribution of preoperative anaemia and blood transfusion or their combination, to adverse patient outcomes. ${ }^{43,44}$ However since both factors are harmful, progress in eliminating the duo in our patients will spare the researchers further arduous task and improve patient safety and care.

\section{White blood cell-filtered red blood cells to the rescue - hopes dashed?}

The use of white blood cell-filtered red blood cells has been adopted in efforts to mitigate the complications associated with allogeneic blood transfusion. Febrile non-hemolytic transfusion reactions (FNHTRs) are the most common adverse event following transfusion of blood products and result mainly from cytokines released by leucocytes and recipient antibodies reacting to donor leucocyte and platelet antigens. Though FNHTRs are generally not life threatening they are associated with considerable management costs and blood product wastage. Leucoreduction has received consistent credit of efficacy in reducing the incidence of febrile nonhaemolytic transfusion reaction in allogeneic red cell recipients. ${ }^{45,46}$ There is also substantial evidence supporting its effectiveness in reducing the transmission of leukocyte-mediated viruses such as cytomegalovirus infection. ${ }^{47}$ Otherwise there is preponderance of data challenging its overall usefulness with a Cochrane review by Simancas-Racines et al. actually concluding that there is no clear evidence for supporting or rejecting the routine use of leukodepleted red cells for preventing transfusion-related acute lung injury and other complications in patients. ${ }^{48}$ While it is incontrovertible that subjecting blood components to leucoreduction provides an additional level of safety for allogeneic red cell transfusion which has led to the implementation of universal leucocyte reduction in many countries, its extensive use has been constrained by its cost relative to the probable clinical benefit it may confer. ${ }^{49}$

\section{Preoperative anaemia in sickle cell disease}

Preoperative anaemia is the case rather than exception among patients with chronic haemolytic anaemia such as sickle cell anaemia and surgery in this subpopulation of patients present with higher morbidity than the general population. The anaemia in sickle cell disease (HbSS) patients is predominantly haemolytic, but iron deficiency anaemia is not uncommon. The low iron stores in some HbSS patients is attributable to same causative factors at play in non- HbSS patients such as poor dietary intake especially during vaso-occlusive crisis, menstrual losses and losses from parasite burden, but the former may in addition have excessive urinary loss of iron from haemolysed red cells. ${ }^{50}$ While red cell destruction is predominantly extravascular in hereditary haemolytic disorders about a third of the haemolysis in HbSS occurs intravascularly. ${ }^{51}$ Intravascular haemolysis liberates haemoglobin into the bloodstream where it binds to haptoglobin while some of the unbound fractions are excreted in the urine, in part as haemosiderin. Otherwise by far the greater concern in HbSS patients is iron overload resulting from frequent red cell transfusions. With exogenous iron accumulation toxicity supervenes resulting in end organ damage involving the liver, heart and endocrine organs. But recent improvements in the management of HbSS patients, among them the use of hydroxyurea have substantially altered the course, impacting on clinical and hematologic indices by increasing $\mathrm{HbF}$, total hemoglobin and reducing transfusion rates. ${ }^{52,53}$ The reported prevalence of iron deficiency at $13.3 \%$ in Yemeni patients with $\mathrm{HbSS},{ }^{54}$ and iron deficiency anaemia prevalence of $67 \%$ in Indian HbSS patients, ${ }^{55}$ suggest that low iron stores contribute significantly to morbidity in these patients. It is instructive that among 8434 subjects in the proportionate sample of rural populations in India iron deficiency was more prevalent in HbSS patients compared to those without the haemoglobinopathy. Thus contrary to widespread presumption, iron deficiency can and does occur among some anaemic sickle cell disease patients. Iron supplementation replenishes iron stores and raises the $\mathrm{Hb}$ levels in iron-deficient sickle cell anaemia patients. ${ }^{55}$ Iron replacement therapy is recommended by current guidelines for HbSS obstetric patients whenever there is laboratory evidence of iron deficiency. ${ }^{56}$ It is presumptive to conclude that the improvement in $\mathrm{Hb}$ level achieved is limited and may not obviate the need for top-up transfusion or exchange blood transfusion in $\mathrm{HbSS}$ patients undergoing major surgeries where reduction of $\mathrm{HbS}$ fraction to $<30 \%$ is crucial. Nevertheless the reduction in the volume of perioperative transfu- 
sion requirement achieved by correction of iron-deficiency in HbSS cannot be discountenanced in patient blood management. Screening for iron deficiency is thus recommended, especially for non-transfused HbSS patients. Management of preoperative anaemia in HbSS patients varies widely among physicians and settings; from operating with steady-state $\mathrm{Hb}$ status to top-up transfusion and exchange blood transfusion. It is however considered that the benefit of correcting preoperative anaemia by red cell transfusion outweighs the risks and costs associated with red cell transfusion in these patients. Evidence from multicentre, randomized controlled trial comparing morbidity in preoperative transfused and non-transfused patients in this group showed higher complication rates in the non-transfused group (39\% versus $15 \%, \mathrm{p}=0.023)$; unadjusted odds ratio 3.8 (95\% CI 1.2-12.2, p=0.027), even for low-medium risk surgeries. ${ }^{57}$ Expert panel report on management of $\mathrm{HbSS}$ strongly recommends correction of preoperative anaemia by red cell transfusion with a target of $10 \mathrm{~g} / \mathrm{dL}$ as this also decreases $\mathrm{HbS}$ fraction and reduces perioperative complications, especially acute chest syndrome. ${ }^{58}$ Top-up transfusion should be preferred to exchange blood transfusion, as its red cell demand and transfusionrelated complications are markedly lower while achieving equivalent efficacy with the latter. ${ }^{59}$ Exchange blood transfusion for correction of preoperative anaemia may be considered for high risk surgeries since it achieves greater reduction of $\mathrm{HbS}$ fraction to $<30 \%$. These guidelines are similar to those of the British society for haematology which recommend preoperative transfusion for $\mathrm{HbSS}$ patients; simple transfusion to $\mathrm{Hb}$ of $10 \mathrm{~g} / \mathrm{L}$ if $\mathrm{Hb}<90 \mathrm{~g} / \mathrm{L}$ or partial exchange if $\mathrm{Hb} \geq 90 \mathrm{~g} / \mathrm{l}$ for patients undergoing low and medium-risk surgery and exchange transfusion for those requiring high-risk surgery. ${ }^{60}$

\section{Iron supplementation with or without ESAs in the correction of preoperative anaemia}

The seeming failure of leukodepleted blood transfusion in mitigating the complications of allogeneic blood transfusion may have energized effort at interventions to prevent red cell transfusion through the correction of preoperative anaemia. The most common cause of preoperative anaemia is iron deficiency, which can be treated with iron supplementation and Erythropoieses-Stimulating Agents (ESAs) enhance the response. Oral iron supplementation may have a role in mitigating preoperative anaemia provided there is sufficient time (6-8 weeks) and adequate tolerance of oral preparations, but even then the benefit may be limited. The increased hepcidin expression associated with inflammation and chronic disorders impairs oral iron absorption, sequesters iron in macrophages and decreases both erythropoietin response to anaemia and erythroid cell response to erythropoietin. In situations of functional iron deficiency such as in inflammatory states, iron stores may be normal but unavailable for erythropoiesis and intravenous iron is required to restore levels of accessible transferrin-bound iron. ${ }^{61-63}$

Several studies have compared the efficacy of the various intravenous iron preparations. Among them Dillon et al. compared the effect of three intravenous iron preparations (iron dextran, iron sucrose and ferric carboxymaltose) on haematological parameters of patients with iron deficiency anaemia and found that the increase in haemoglobin concentration was significantly greater with both iron sucrose and ferric carboxymaltose compared to iron dextran ( $\mathrm{p}=0.04$ and $<0.01$, respectively) but with no statistically significant difference between the groups treated with iron sucrose and ferric carboxymaltose. ${ }^{64}$ They also noted significant increase in mean serum ferritin concentration after treatment in all groups but without a statistically significant difference between the groups. Findings from a systematic review on the use of intravenous iron in pregnant women with iron-deficiency anaemia revealed that whereas iron sucrose was overwhelmingly used no preparation of IV iron appeared to be superior, rather it was noted that cost and convenience of administration largely determined their use. ${ }^{65}$ The product prices of ferric carboxymaltose and iron isomaltoside are significantly higher than iron sucrose and iron dextran. In spite of this however the incidental costs of multidosing downgrades the older formulations to a more costly form of therapy. ${ }^{66}$ The incidence of severe adverse events including anaphylactic reactions is extremely low with the new intravenous iron preparations while infusion reaction, which is the main adverse effect, is infrequent and usually requiring no treatment compared to the gastrointestinal events which are very common with oral iron therapy, often leading to non-compliance with therapy. There is however exception for the iron dextran formulations which are notorious for hypersensitivity reactions. While high molecular weight iron dextran has since been withdrawn in most counties, low molecular weight iron dextran which supplanted it since the 1990s, has been of great utility for many clinicians wishing to administer single large doses of iron. Since the isolation of endogenous erythropoietin from human urine in 1977 and subsequent license of recombinant human erythropoietin in 1988, the latter has been extensively used in healthcare to stimulate red blood cell production, correct anaemia and reduce allogeneic blood transfusions. Available ESAs include recombinant human erythropoietins (erythropoietin, epoetin alfa, epoetin beta, epoetin zeta, darbepoetin alfa) and continuous erythropoietin receptor activator (CERA). The ESAs increase the number of red blood cells within about 2 to 3 weeks and their efficacy in stimulating erythropoiesis is dose-dependent. ESAs are listed among the WHO essential drugs list and are remarkably well tolerated but adverse effects such as hypertension and thrombotic events have been reported in some patients, especially those with renal failure. Comparative studies on their efficacy and safety suggests that there is no clinically significant difference between the various ESAs in haemoglobin response, transfusion reduction and adverse events. ${ }^{67}$ However there have been recent concerns that ESAs may enhance tumor progression or decrease patient survival. ${ }^{68,69}$ In the face of seeming contradictory conclusions from systematic reviews and meta-analyses regarding these outcomes, ${ }^{70,71}$ and given that ESAs are widely used to treat anaemia in cancer patients, consideration for the potential detrimental effects should be balanced against the benefits of treatment with ESAs taking into account each patient's clinical circumstances and available options.

\section{Outcome of interventions at correcting preopera- tive anaemia in elective surgeries}

There are many studies reporting the outcome of interventions to correct preoperative anaemia (Table 1). Many of these evaluated the impact of iron therapy while some investigated the efficacy of ESAs and others assessed the impact of therapy with combination of iron and ESAs. Most studies however confirmed that preoperative iron supplementation and ESA therapy; independently or in combination are effective in correcting preoperative anaemia.

Several studies have been conducted to compare the efficacy of combination of iron and ESA with either therapy used alone. Among them a Cochrane systematic review evaluated the benefits 
and adverse events related to the use of iron as a supplement to ESA and ESA alone in the management of chemotherapy-induced anaemia and concluded that addition of iron to ESAs is safe and offers superior haemopoietic response, but with no influence on the median time to haemopoietic response. ${ }^{82}$

\section{Opportunities in orthopaedics, oncology, cardiac surgery, bariatrics, obstetrics and gynaecology surgeries}

With the aging global population the number and proportion of older adults are increasing. As anaemia prevalence rates rise after age 50 years an increasing incidence of preoperative anaemia in the surgical patient population could be envisaged. Orthopedic surgeries especially spine surgery and arthroplasty surgery, are associated with excessive bleeding and a high potential for blood transfusion requirement. These surgeries which are predominantly elective procedures and common in the elderly will challenge the practice of patient blood management as proper scheduling to facilitate optimisation of preoperative anaemia is only rational. It is thus not surprising that orthopaedics has got a fair share of the many interventions to correct preoperative anaemia. ${ }^{73-75,77,78,81}$

The incidence of preoperative anaemia is relatively high among cancer patients being influenced by a combination of reduced nutrient intake, cancer related blood loss, increased hepcidin expression with impaired absorption and utilization of stored iron, inflammatory cytokine -mediated reduction in erythropoietin production, blunting of erythropoietin sensitivity and reduced red cell life span. In the review conducted by Varloto and Stevenson on the impact of anemia and tumor hypoxemia on survival in cancer patients, they reported anaemia incidence of $40-64 \%$ at presenta- tion which rises as therapy commenced. ${ }^{83}$ They also confirmed a correlation between low hemoglobin levels and higher amounts of tumor hypoxia and consequent resistance to chemotherapy and radiotherapy. But rather unfortunately perioperative blood transfusion has been proven to worsen cancer recurrence and mortality in cancer patients. ${ }^{37}$ Indeed it might appear that cancer patients could benefit most from correction of preoperative anaemia since the benefit of the intervention in elevating $\mathrm{Hb}$ in the postoperative period will confer the additional benefit of preventing resistance to subsequent chemotherapy or radiotherapy ascribed to tumour hypoxia.

Preoperative anemia has been independently associated with long-term mortality in cardiac surgery patients. ${ }^{30}$ Transfusion requirement encountered during cardiac surgery can be quite considerable with data from patients undergoing isolated or combined CABG in Brazil indicating a transfusion rate of $64 \%$, and blood transfusion carried a 2-3 fold higher risk of morbidity and mortality. ${ }^{84}$ These indices arguably make correction of preoperative anaemia a good target for morbidity and mortality improvement in cardiac surgery.

The elective nature of many gynaecological and obstetric procedures offers opportunity for $\mathrm{Hb}$ optimization in the patients with preoperative anaemia. Owing to the prevalent preoperative anaemia in many of these patients, the potential for substantial blood loss in the procedures could make allogeneic blood transfusion inevitable if preoperative anaemia is not corrected. Richards et al. had evaluated the impact of preoperative anaemia and blood transfusion on 12,836 females who underwent gynaecological surgeries in the American College of Surgeons National Surgical Quality Improvement Program. With a reported prevalence at $23.9 \%$ in the cohort, preoperative anaemia was found to be a predictor for mortality and morbidity, while any concomitant blood

Table 1. Outcome of iron and erythropoietin interventions in the treatment of preoperative anaemia.

\begin{tabular}{|c|c|c|c|c|}
\hline Study & Sample & Treatment group & Measure & Significance \\
\hline $\begin{array}{l}\text { Bhavi et al. } \\
2017 \text { [72] }\end{array}$ & $\begin{array}{l}\text { Obstetrics } \\
(\mathrm{n}=112)\end{array}$ & I.V iron versus oral iron & $\begin{array}{l}\text { Difference between the two groups in mean Hb increase } \\
\text { Difference between the two groups in mean serum ferritin increase }\end{array}$ & $\begin{array}{c}\mathrm{NS} \\
\mathrm{P}<0.0001\end{array}$ \\
\hline $\begin{array}{l}\text { Biboulet et al. } \\
2018 \text { [73] }\end{array}$ & $\begin{array}{l}\text { Orthopaedics } \\
(\mathrm{n}=100)\end{array}$ & $\begin{array}{l}\text { Epo plus oral iron versus } \\
\text { Epo plus iv iron }\end{array}$ & $\begin{array}{l}\text { Rise in } \mathrm{Hb} \\
\text { Serum ferritin } \\
\text { Incidence of gastrointestinal adverse effects }\end{array}$ & $\begin{array}{l}P<0.001 \\
P<0.001 \\
P<0.001\end{array}$ \\
\hline $\begin{array}{l}\text { Hourlier et al. } \\
2020 \text { [74] }\end{array}$ & $\begin{array}{l}\text { Orthopaedics } \\
(\mathrm{n}=1402)\end{array}$ & High versus low dose Epo & Rise in $\mathrm{Hb}$ & $\mathrm{P}<0.001$ \\
\hline $\begin{array}{l}\text { Rosencher et al. } \\
2005 \text { [75] }\end{array}$ & $\begin{array}{l}\text { Orthopaedics } \\
(\mathrm{n}=100)\end{array}$ & Epo versus PADB & $\begin{array}{l}\text { Volume of red cells produced } \\
\text { Patients transfused allogeneic blood (\%) } \\
\text { Quality of life }\end{array}$ & $\begin{array}{c}\mathrm{P}<0.0001 \\
12.6 \% \text { versus } 6.6 \% \mathrm{NS} \\
\mathrm{P}=0.004\end{array}$ \\
\hline $\begin{array}{l}\text { Yoo et al. } \\
2011[76]\end{array}$ & $\begin{array}{l}\text { Heart surgery } \\
(\mathrm{n}=74)\end{array}$ & Epo plus I.V iron versus control & $\begin{array}{l}\text { Number of patients transfused with allogeneic red cells. } \\
\text { Mean number of units of packed cells transfused per patient. }\end{array}$ & $\begin{array}{l}P=0.009 \\
P=0.001\end{array}$ \\
\hline $\begin{array}{l}\text { Kurian et al. } \\
2019[77]\end{array}$ & $\begin{array}{l}\text { Orthopaedics } \\
(\mathrm{n}=160)\end{array}$ & $\begin{array}{l}\text { I.V iron, Epo, i.v iron } \\
\text { plus Epo versus control }\end{array}$ & $\begin{array}{l}\text { Median increase in preoperative } \mathrm{Hb} \\
\text { Mean postop. nadir } \mathrm{Hb}\end{array}$ & $\begin{array}{l}P<0.001 \\
P<0.001\end{array}$ \\
\hline $\begin{array}{l}\text { Lachance et al. } \\
2011 \text { [78] }\end{array}$ & $\begin{array}{l}\text { Orthopaedics } \\
(\mathrm{n}=87)\end{array}$ & Oral iron supplementation & $\begin{array}{l}\text { Drop in mean } \mathrm{Hb} \\
\text { Mean rise in serum ferritin }\end{array}$ & $\begin{array}{l}\mathrm{P}=0.015 \\
\mathrm{P}<0.001\end{array}$ \\
\hline $\begin{array}{l}\text { Simpson et al. } \\
2010[79]\end{array}$ & $\begin{array}{l}\text { Colorectal cancer } \\
(\mathrm{n}=10)\end{array}$ & Single dose I.V iron & Mean rise in $\mathrm{Hb}$ & $\mathrm{P}=0.036$ \\
\hline $\begin{array}{l}\text { Keeler et al. } \\
2017[80]\end{array}$ & $\begin{array}{l}\text { Colorectal cancer } \\
(\mathrm{n}=116)\end{array}$ & Oral iron versus I.V iron & $\begin{array}{l}\text { Median increase in } \\
\text { preop } \mathrm{Hb}\end{array}$ & $\mathrm{P}<0.001$ \\
\hline $\begin{array}{l}\text { Munoz et al. } \\
2009 \text { [81] }\end{array}$ & $\begin{array}{l}\text { Gynaecology, } \\
\text { orthopaedics, } \\
\text { colon cancer } \\
(\mathrm{n}=84)\end{array}$ & I.V iron & Mean rise in $\mathrm{Hb}$ & $\mathrm{P}<0.001$ \\
\hline
\end{tabular}

NS: not significant; Epo: erythropoietin; PADB: preoperative autologous blood donation. 
transfusion further worsened these outcomes. ${ }^{85}$ In a prospective study to determine the risk factors for blood transfusion during caesarian deliveries in Nigeria preoperative $\mathrm{PCV}<26 \%(\mathrm{OR}=33.8$, 95\% CI $=11.8-97.0$ ) emerged a major indicator of blood transfusion. ${ }^{86}$ In the study the mean preoperative PCV $( \pm$ S.D) was $34.15 \pm 3.6 \mathrm{~g} / \mathrm{dL}$ and $28.77 \pm 6.5 \mathrm{~g} / \mathrm{dL}$ respectively for those who were not transfused and those who were transfused $(p<0.0001)$. The importance of optimizing preoperative anaemia in obstetrics care thus assumes even greater significance with the global rise in caesarian deliveries. ${ }^{87}$ With the increasing prevalence of obesity worldwide bariatric surgeries are increasingly being done for the management of obesity and its associated conditions owing to the drastic weight loss it offers compared to non-surgical treatment. Although blood loss is not considerable following bariatric surgery the procedure increases the risk of developing iron deficiency and anaemia after surgery. Moreover preoperative anemia or iron deficiency are commonly found in bariatric surgery patients, and are associated with an increased postoperative morbidity. Recent developments in obesity research have confirmed that the disorder is associated with chronic, low-grade, systemic inflammation. Results of a meta-analysis assessing the concentration of haematological iron markers and the risks associated with iron deficiency in 13,393 overweight/obese individuals and 26,621 non-overweight participants indicate that overweight/obese participants had a significantly increased risk of iron deficiency (OR:1.31;95\% $\mathrm{CI}=1.01-1.68) .{ }^{88}$ Low iron status is a common and predominant preoperative micronutrient deficiency seen in obese individuals undergoing bariatric surgery and usually worsens after surgery. From a Dutch study of a group of 427 gastric bypass patients, iron was the most common preoperative deficiencies, worsening in the postoperative period, and preoperative iron deficiency emerged a risk factor for developing a post-operative deficiency despite supplementation. ${ }^{89}$ Iron deficiency is frequently encountered in patients before and after bariatric surgery from a combination of increased hepcidin expression and reduced absorption due to bypass of the duodenum (iron absorption site) in gastric bypass procedures such as Roux-en-Y gastric bypass and biliopancreatic diversion with duodenal switch gastric bypass. Suboptimal conversion of absorption of $\mathrm{Fe}^{3+}$ to readily absorbable $\mathrm{Fe}^{2+}$ by gastric acid after gastric reduction procedures is also thought to play a role. Consequently oral iron supplementation often have limited efficacy before or after bariatric surgery. Notwithstanding that most of the studies on iron supplementation relating to bariatric surgery have been conducted in the post-surgical phase evidence from the foregoing provide sufficient ground for the preoperative evaluation and correction of iron deficiency states in bariatric surgery patients with intravenous iron.

\section{Barriers to preoperative haemoglobin optimisa- tion in surgical patients}

It is commonplace for preoperative anaemia to be relegated as mere abnormal laboratory report while allogeneic blood is provided to be transfused as needed, and surgery proceeds as planned. Quite often too, iron supplementation has been regarded as anathema in $\mathrm{HbSS}$ patients owing to the assumption of universal iron overload status in them. Similarly, misconception and misapplication of the concept of restrictive transfusion and transfusion trigger is on a large scale in clinical practice settings. The Canadian transfusion requirement in critical care (TRICC) trial, ${ }^{90}$ had provided ample evidence that restrictive transfusion strategy (adoption of transfusion trigger of $7 \mathrm{~g} / \mathrm{dL}$ ) provides a better outcome than liberal transfusion strategy (adoption of transfusion trigger of $10 \mathrm{~g} / \mathrm{dL}$ ). Quite unfortunately not a few surgeons and anaesthetists have misunderstood and misapplied the concept of restrictive transfusion using a low transfusion trigger of $8 \mathrm{~g} / \mathrm{dL}$ to mean a new paradigm of listing and routinely carrying out major elective surgical procedures on patients with preoperative anaemia of $8 \mathrm{~g} / \mathrm{dL}$, with provision of a good stock of allogeneic blood on standby.

It is conceivable that some centres that offer fast-track surgical service to patients may in practice waive pre-operative patient optimization with regard to preoperative anaemia correction due to the time required. It must however be realised that the benefits from same-day admission derive from it forming the final stage of a comprehensive pre-operative optimization programme. Evidence that preoperative anaemia and the need for blood transfusion influence postoperative outcome, length of stay and patient satisfaction in patients, ${ }^{91}$ should galvanise greater priority for optimizing preoperative anaemia in "Enhanced Recovery After Surgery" (ERAS) care pathways. The benefits derivable from preoperative optimization of patients, with reduction in morbidity and shorter length of stay after fast-track surgery was further highlighted in the review by Kehlet and Thienpont. ${ }^{92}$ Hence it would suffice to say that preoperative optimisation, including the correction of anaemia is core to the fast-track surgery concept and fast-track service has a vantage position to champion the advocacy. I dare say that addressing preoperative anemia qualifies as a key component of fast-track protocols.

Despite overwhelming evidence mandating the correction of preoperative anaemia prior to major surgeries the cost of erythropoiesis stimulating agents and intravenous iron formulations which are the cornerstone of this intervention have remained prohibitive, especially for low-resource settings. Oral iron is effective and quite affordable but its shortcomings that necessitate intravenous iron therapy (slow response, impaired absorption in gastrointestinal pathology and inflammatory conditions, poor compliance owing to intolerance to side effects, short time to surgery) almost mutually exclude oral iron therapy.

\section{Conclusions}

Compelling evidence attests to the efficacy and safety profile of intravenous iron administration and ESAs for the rapid correction of preoperative anaemia in surgical patients. However the realisation of this lofty potential may be constrained by misconceptions among clinicians and the prohibitive cost of the products, especially in poor resource settings.

\section{References}

1. Sixty-Third World Health Assembly. Availability, safety and quality of blood products. 2010. Available from: https://apps. who.int/gb/ebwha/pdf_files/WHA63/A63_R12-en.pdf. Accessed on May 1, 2020.

2. Isbister JP. The three-pillar matrix of patient blood management-an overview. Best Pract Res Clin Anaesthesiol 2013;27:69-84.

3. Wu WC, Schifftner TL, Henderson WG, et al. Preoperative hematocrit levels and postoperative outcomes in older patients undergoing noncardiac surgery. JAMA 2007;297:2481-8.

4. Seicean A, Seicean S, Alan N, et al. Preoperative anemia and perioperative outcomes in patients who undergo elective spine 
surgery. Spine (Phila Pa 1976) 2013;38:1331-41.

5. Fowler AJ, Ahmad T, Phull MK, et al. Meta-analysis of the association between preoperative anaemia and mortality after surgery. Br J Surg 2015;102:1314-24.

6. Kotze A, Harris A, Baker C, et al. British Committee for Standards in Haematology Guidelines on the Identification and Management of Pre-Operative Anaemia. Br J Haematol 2015;171:322-31.

7. Goodnough LT, Maniatis A, Earnshaw P, et al. Detection, evaluation, and management of preoperative anaemia in the elective orthopaedic surgical patient: NATA guidelines. $\mathrm{Br} \mathrm{J}$ Anaesth 2011;106:13-22.

8. Kozek-Langenecker SA, Afshari A, Albaladejo P, et al. Management of severe perioperative bleeding: guidelines from the European Society of Anaesthesiology. Eur J Anaesthesiol 2013;30:270-382.

9. Gombotz H, Rehak PH, Shander A, Hofmann A. Blood use in elective surgery: the Austrian benchmark study. Transfusion 2007;47:1468-80.

10. Shander A, Javidroozi M, Ozawa S, Hare GM. What is really dangerous: anaemia or transfusion? Br J Anaesth 2011;107: i41-59.

11. Muñoz M, Laso-Morales MJ, Gómez-Ramírez S, et al. Preoperative haemoglobin levels and iron status in a large multicentre cohort of patients undergoing major elective surgery. Anaesthesia 2017;72:826-34.

12. Kearney B, To J, Southam K, Howie D, To B. Anaemia in elective orthopaedic surgery - Royal Adelaide Hospital, Australia. Intern Med J 2016;46:96-101.

13. Kassebaum NJ, Jasrasaria R, Naghavi M, et al. A systematic analysis of global anemia burden from 1990 to 2010. Blood 2014;123:615-24.

14. Baltussen R, Knai C, Sharan M. Iron fortification and iron supplementation are cost-effective interventions to reduce iron deficiency in four subregions of the world. J Nutr 2004; 134:2678-84.

15. World Health Organization. Guidelines on food fortification with micronutrients. Available from: http://apps.who.int/iris/ bitstream/10665/43412/1/9241594012_eng.pdf?ua=1. Accessed on May 1, 2020.

16. Weatherall DJ. The inherited diseases of hemoglobin are an emerging global health burden. Blood 2010;115:4331-6.

17. Musallam KM, Tamim HM, Richards T, et al. Preoperative anaemia and postoperative outcomes in non-cardiac surgery: a retrospective cohort study. Lancet 2011;378:1396-407.

18. Gupta PK, Sundaram A, Mactaggart JN, et al. Preoperative anemia is an independent predictor of postoperative mortality and adverse cardiac events in elderly patients undergoing elective vascular operations. Ann Surg 2013;258:1096-102.

19. Amponsah G, Alice Charwudzi A. Preoperative Anaemia and Associated Postoperative Outcomes in Noncardiac Surgery Patients in Central Region of Ghana. Anesthesiol Res Pract 2017; 2017:7410960.

20. Saager L, Turan A, Reynolds LF, et al. The association between preoperative anemia and 30-day mortality and morbidity in noncardiac surgical patients. Anesth Analg 2013;117:909-15.

21. White MC, Longstaff L, Lai PS. Effect of pre-operative anaemia on post-operative complications in low-resource settings. World J Surg 2017;41:644-9.

22. Fowler AJ, Ahmad T, Abbott TEF, et al. on behalf of the International Surgical Outcomes Study Group. Association of preoperative anaemia with postoperative morbidity and mortality: an observational cohort study in low-, middle-, and high-income countries. Br J Anaesth 2018;121:1227-35.

23. Greenky M, Gandhi K, Pulido L, et al. Preoperative anemia in total joint arthroplasty: is it associated with periprosthetic joint infection? Clin Orthop Relat Res 2012;470:2695-701.

24. Grosso MJ, Boddapati V, Cooper HJ, et al. The Effect of Preoperative Anemia on Complications After Total Hip Arthroplasty. J Arthroplasty 2020;35:S214-S218.

25. Abdullah HR, Sim YE, Hao Y, Lin GY, Liew GHC, Lamoureux EL, et al. Association between preoperative anaemia with length of hospital stay among patients undergoing primary total knee arthroplasty in Singapore: a single-centre retrospective study. BMJ Open 2017;7:e016403.

26. Baron DM, Hochrieser H, Posch M, et al. European Surgical Outcomes Study (EuSOS) group for Trials Groups of European Society of Intensive Care Medicine; European Society of Anaesthesiology. Preoperative anaemia is associated with poor clinical outcome in non-cardiac surgery patients. Br J Anaesth 2014;113:416-23.

27. Bydon M, Abt NB, Macki M, et al. Preoperative anemia increases postoperative morbidity in elective cranial neurosurgery. Surg Neurol Int 2014;5:156.

28. Wu WC, Schifftner TL, Henderson WG, et al. Preoperative hematocrit levels and postoperative outcomes in older patients undergoing noncardiac surgery. JAMA 2007;297:2481-8.

29. Gabriel RA, Clark AI, Nguyen AP, et al. The association of preoperative hematocrit and transfusion with mortality in patients undergoing elective non-cardiac surgery. World J Surg 2018;42:1939-48.

30. Padmanabhan H, Brookes MJ, Nevill AM, Luckraz H. Association between anemia and blood transfusion with longterm mortality after cardiac surgery. Ann Thorac Surg 2019;108:687-92.

31. Cushner FD, Friedman RJ. Blood loss in total knee arthroplasty. Clin Orthop Relat Res 1991;269:98-101.

32. Kwon HY, Kim BR, Kim YW. Association of preoperative anemia and perioperative allogenic red blood cell transfusion with oncologic outcomes in patients with nonmetastatic colorectal cancer. Curr Oncol 2019;26:e357-e366.

33. Ristagno G, Beluffi S, Tanzi D, et al. Red blood cell transfusion need for elective primary posterior lumbar fusion in a highvolume center for spine surgery. J Clin Med 2018;7:19.

34. Mufarrih SH, Qureshi NQ, Ali A, et al. Total knee Arthroplasty: risk factors for allogeneic blood transfusions in the South Asian population. BMC Musculoskelet Disord 2017;18:359.

35. Saleh E, McClelland DBL, Hay A, et al. Prevalence of anaemia before major joint arthroplasty and the potential impact of preoperative investigation and correction on perioperative blood transfusions. Br J Anaesth 2007;99:801-8.

36. Jensen LS, Andersen AJ, Christiansen PM, et al. Postoperative infection and natural killer cell function following blood transfusion in patients undergoing elective colorectal surgery. Br J Surg 1992;79:513-6.

37. Qiu L, Wang DR, Zhang XY, et al. Impact of perioperative blood transfusion on immune function and prognosis in colorectal cancer patients. Transfus Apher Sci 2016;54:235-41.

38. Richards T, Musallam KM, Nassif J, et al. Impact of preoperative anaemia and blood transfusion on postoperative outcomes in gynaecological surgery. PLoS ONE 2015;10:e0130861.

39. Koch CG, Li L, Duncan AI, et al. Morbidity and mortality risk associated with red blood cell and blood-component transfusion in isolated coronary artery bypass grafting. Crit Care Med 2006;34:1608-16.

40. Ferraris VA, Davenport DL, Saha SP, et al. Surgical outcomes 
and transfusion of minimal amounts of blood in the operating room. Arch Surg 2012;147:49-55.

41. Bower WF, Jin L, Underwood MJ, et al. Peri-operative blood transfusion increases length of hospital stay and number of postoperative complications in non-cardiac surgical patients. Hong Kong Med J 2010;16:116-20.

42. Wright JG, Einhorn TA, Heckman JD. Grades of recommendation. J Bone Joint Surg Am 2005;87:1909-10.

43. LaPar DJ, Hawkins RB, McMurry TL, et al. Investigators for the Virginia Cardiac Services Quality Initiative. Preoperative anemia versus blood transfusion: Which is the culprit for worse outcomes in cardiac surgery? J Thorac Cardiovasc Surg 2018; 156:66-74.e2.

44. Loor G, Rajeswaran J, Li L, et al. The least of 3 evils: exposure to red blood cell transfusion, anemia, or both? J Thorac Cardiovasc Surg 2013;146:1480-7.e6.

45. Rajesh K, Harsh S, Amarjit K. Effects of prestorage leukoreduction on the rate of febrile nonhemolytic transfusion reactions to red blood cells in a tertiary care hospital. Ann Med Health Sci Res 2015;5:185-8.

46. Paglino JC, Pomper GJ, Fisch GS, et al. Reduction of febrile but not allergic reactions to RBCs and platelets after conversion to universal prestorage leukoreduction. Transfusion 2004; 44:16-24.

47. Vamvakas EC. Is white blood cell reduction equivalent to antibody screening in preventing transmission of cytomegalovirus by transfusion? A review of the literature and meta-analysis. Transfus Med Rev 2005;19:181-99.

48. Simancas-Racines D, Osorio D, Marti-Carvajal A, ArevaloRodriguez I. Leukodepleted for the prevention of adverse reactions from allogeneic blood transfusion. Cochrane Database Syst Rev 2015;12:CD009745.

49. Tsantes AE, Kyriakou E, Nikolopoulos GK, et al. Cost-effectiveness of leucoreduction for prevention of febrile nonhaemolytic transfusion reactions. Blood Transfus 2014;12:232-7.

50. Millot S, Delaby C, Moulouel B, et al. Hemolytic anemia repressed hepcidin level without hepatocyte iron overload: lesson from Günther disease model. Haematologica 2017;102:260-70.

51. Embury SH, Vichinsky EP. Sickle cell disease. In: Hoffman R, BenzEJ, Shattil SJ, et al. (eds.) Hematology. Basic principles and practice. New York: Churchill Livingstone; 2000. p 522.

52. Keikhaei B, Yousefi H, Bahadoram M. Hydroxyurea: clinical and hematological effects in patients with sickle cell anemia. Glob J Health Sci 2015;8:252-6.

53. Agrawal RK, Patel RK, Shah V, et al. Hydroxyurea in sickle cell disease: drug review. Indian J Hematol Blood Transfus 2014;30:91-6.

54. Kassim A, Thabet S, Al-Kabban M, Al-Nihari K. Iron deficiency in Yemeni patients with sickle-cell disease. East Mediterr Health J 2012;18:241-5.

55. Mohanty D, Mukherjee MB, Colah RB, et al. Iron deficiency anaemia in sickle cell disorders in India. Indian J Med Res 2008;127:366-9.

56. Royal College of Obstetricians and Gynaecologists. Management of sickle cell disease in pregnancy. Green-top Guideline 2011;61. Available from: https://www.rcog.org.uk/globalassets/documents/guidelines/gt g_61.pdf. Accessed on June 8, 2020.

57. Howard J, Malfroy M, Llewelyn C, et al. The Transfusion Alternatives Preoperatively in Sickle Cell Disease (TAPS) study: a randomised, controlled, multicentre clinical trial.
Lancet 2013;381:930-8.

58. Yawn BP, Buchanan GR, Afenyi-Annan AN, et al. Management of sickle cell disease: summary of the 2014 evidence-based report by expert panel members. JAMA 2014;312:1033-48.

59. Vichinsky EP, Haberkern CM, Neumayr L, et al. A comparison of conservative and aggressive transfusion regimens in the perioperative management of sickle cell disease. The Preoperative Transfusion in Sickle Cell Disease Study Group. N Engl J Med 1995;333:206-13.

60. Davis BA, Allard S, Qureshi A, et al. on behalf of the British Society for Haematology. Guidelines on red cell transfusion in sickle cell disease Part II: indications for transfusion. Br J Haematol 2017;176:192-209.

61. Eisenga MF, Bakker SJ, Gaillard CA. Definition of functional iron deficiency and intravenous iron supplementation. Lancet Haematol 2016;3:e504.

62. Thomas DW, Hinchliffe RF, Briggs C, et al. British Committee for Standards in Haematology. Guideline for the laboratory diagnosis of functional iron deficiency. $\mathrm{Br} \mathrm{J}$ Haematol 2013;161:639-48.

63. Goodnough LT, Nemeth E, Ganz T. Detection, evaluation, and management of iron-restricted erythropoiesis. Blood 2010;116:4754-61.

64. Dillon R, Momoh I, Francis Y, et al. Comparative efficacy of three forms of parenteral Iron. J Blood Transfus 2012; Article ID 473514.

65. Qassim A, Mol BW, Grivell RM, Grzeskowiak LE. Safety and efficacy of intravenous iron polymaltose, iron sucrose and ferric carboxymaltose in pregnancy: A systematic review. Aust N Z J Obstet Gynaecol 2018;58:22-39.

66. Bhandari S. Update of a comparative analysis of cost minimization following the introduction of newly available intravenous iron therapies in hospital practice. Ther Clin Risk Manag 2011;7:501-9.

67. Grant MD, Piper M, Bohlius J, et al. Epoetin and darbepoetin for managing anemia in patients undergoing cancer treatment: comparative effectiveness update. Rockville (MD): Agency for Healthcare Research and Quality (US); 2013 Apr. Report No.:13-EHC077-EF.

68. Wu P, Zhang N, Wang X, et al. The erythropoietin/erythropoietin receptor signaling pathway promotes growth and invasion abilities in human renal carcinoma cells. PLoS One 2012;7:e45122.

69. Leyland-Jones B, Semiglazov V, Pawlicki M, et al. Maintaining normal hemoglobin levels with epoetin alfa in mainly nonanemic patients with metastatic breast cancer receiving first-line chemotherapy: a survival study. J Clin Oncol 2005;23:5960-72.

70. Bohlius J, Tonia T, Schwarzer G. Twist and shout: one decade of meta-analyses of erythropoiesis-stimulating agents in cancer patients. Acta Haematol 2011;125:55-67.

71. Glaspy J, Crawford J, Vansteenkiste J, et al. Erythropoiesisstimulating agents in oncology: a study-level meta-analysis of survival and other safety outcomes. Br J Cancer 2010;102:30115.

72. Bhavi SB, Jaju PB. Intravenous iron sucrose $\mathrm{v} / \mathrm{s}$ oral ferrous fumarate for treatment of anemia in pregnancy. A randomized controlled trial. BMC Pregnancy Childbirth 2017;17:137.

73. Biboulet P, Bringuier S, Smilevitch P, et al. Preoperative epoetin- $\alpha$ with intravenous or oral iron for major orthopedic surgery. A randomized controlled trial. Anesthesiology 2018;129:710-20. 
Database Syst Rev 2016;2:CD009624.

83. Varlotto J, Stevenson MA. Anemia, tumor hypoxemia, and the cancer patient. Int J Radiat Oncol Biol Phys 2005;63:25-36.

84. Campos IC, Tanganelli V, Maues HP, et al. Blood transfusion and increased perioperative risk in coronary artery bypass grafts. Braz J Cardiovasc Surg 2017;32:394-400.

85. Richards T, Musallam KM, Nassif J, et al. Impact of preoperative anaemia and blood transfusion on postoperative outcomes in gynaecological surgery. PLoS One 2015;10:e0130861.

86. Eyelade OR, Adesina OA, Adewole IF, Adebowale SA. Blood transfusion requirement during caesarean delivery: risk factors. Ann Ib Postgrad Med 2015;13:29-35.

87. Wise J. Alarming global rise in caesarean births, figures show. BMJ 2018;363:k4319.

88. Zhao L, Zhang X, Shen Y, et al. Obesity and iron deficiency: a quantitative meta-analysis. Obes Rev 2015;16:1081-93.

89. van der Beek ES, Monpellier VM, Eland I, et al. Nutritional deficiencies in gastric bypass patients; incidence, time of occurrence and implications for post-operative surveillance. Obes Surg 2015;25:818-23.

90. Hébert PC, Wells G, Blajchman MA, et al. A multicenter, randomized, controlled clinical trial of transfusion requirements in critical care. Transfusion Requirements in Critical Care Investigators, Canadian Critical Care Trials Group. N Engl J Med 1999;340:409-17.

91. Husted H, Holm G, Jacobsen S. Predictors of length of stay and patient satisfaction after hip and knee replacement surgery: fast-track experience in 712 patients. Acta Orthop 2008;79: 168-7.

92. Kehlet H, Thienpont E. Fast-track knee arthroplasty — status and future challenges. Knee 2013;20:S29-33. 